\title{
"Endless Possibilities" Embodied Experiences and Connections in Social Salsa Dancing
}

\author{
B. MCCluRe
}

There's only one place to go, and that's here [points to himself]. And because we're dealing with infinity, we're dealing with endless possibility, then all of us are at zero. (Frankie)

You become more aware of your body, what your body can do ... there is room to grow, there is room to develop, and you're actually able to cover that distance. (Heike)

The embodied self can be understood as an object, worked upon by bodily practices that enact and perpetuate normative ideals. This perception of bodies tends to be dominated by visual judgments, setting up prescriptive trajectories of self-cultivation towards idealized body images (see Young, Bordo, Mulvey). Yet the embodied self can also be understood as a subject which engages in bodily practices as a way of negotiating personal freedom against normative ideals (see Shusterman, Heyes). This article represents part of a wider doctoral project which explores the tensions between these perspectives through a detailed empirical case-study of social salsa dancing as an embodied, intersubjective and affective practice. The existing literature on social salsa dancing focuses on issues of ethnicity, cosmopolitanism and globalization (see Pušnik and Sicherl, Johnson, Gibson, Pietrobruno, Kapchan), cultural commodification (see Pušnik and Sicherl, Urquia, and Schneider, Community), and gender roles and relations (see Borland, Skinner, and Schneider Heteronormativity). Whilst these are clearly important issues, there has been very little exploration of the subjective experience or affirmative potential of social salsa dancing in terms of selfcultivation. Therefore, whilst recognizing that social salsa dancing is far from being free of normative pressures, in this article I wish to focus in particular on the affirmative aspects of its potential as a context in which we can learn to make sense of our bodies in ways other than through 
visual judgments. I make the case that social salsa dancing emphasizes and cultivates kinesthetic, tactile, and musical senses and values, opening up capacities for making sense of ourselves and others in terms of a process of being-a-body-with-other-bodies. By focusing attention on the immediate experience of our interactions and momentary connections with others, we can conceptualize working on our embodied self less in terms of a trajectory towards an ideal, and more in terms of exploring possibilities within these interactions and momentary connections.

This article is framed by well established theoretical perspectives on embodiment and bodily practices, in particular Merleau-Ponty's concept of the "reversible body" and Foucault's concept of subjectification. In the first section, I outline how these perspectives are useful for conceiving of the embodied self as both an object and a subject, but also show how vision tends to dominate our perception of bodies, causing us to make judgments against normalized or idealized body images. Drawing together ideas of bodily attention from various fields and disciplines, I provide a theoretical context for bodily practices which emphasize the process of being a body and develop senses and values which are not primarily concerned with visual perception and judgment. These ideas are then explored in the rest of the article through the empirical study of social salsa dancing. It is important to clarify that the term salsa is often used to refer to an array of different dance forms, musical genres, and social contexts; salsa is sometimes choreographed and danced by couples, teams or solo, performed in front of spectators or competitively in front of judges on a stage, or simplified into exercise routines for gym classes. However, the focus of this study is social salsa dancing, which is improvised with constantly changing partners and danced informally for pleasure, and particularly social salsa dancing at international festivals known as congresses. The empirical findings presented this article were gathered through a highly participatory approach to fieldwork and informed by a decade of personal experience within the social salsa community.

\section{Embodiment and Bodily Practices}

Theories of the self have struggled with the legacy handed down from Descartes and other key philosophers of the Enlightenment period in terms of conceptualizing the self as a conscious mind within a physical body. In The Phenomenology of Perception, Maurice Merleau-Ponty posed one of the most influential challenges to this approach by arguing that our engagement with the world is always as experienced through our body, thus placing the issue of embodiment centre stage. Merleau-Ponty offers a concept of the "reversible body", simultaneously perceiving and being perceived, both the subject of an ongoing experiential present and an object caught in the perceptual field of others. It is important to recognize 
the difference between Merleau-Ponty's concept of reversibility and Cartesian dualism. Instead of splitting body and mind-where body is equated to object, and mind to subject-Merleau-Ponty unites body and mind in a being that exists simultaneously as a conscious, active agent, and a physical object within the world. Thus the mindful, embodied individual is at once both visible and seeing, tangible and touching, in space and spatially orientated.

Michel Foucault theorizes this dual existence in terms of "modes of objectification," arguing that visual observation and examination of others have historically proven to be critical techniques for determining the criteria for what constitutes a "normal" human subject, and for classifying individuals according to those criteria. In an approach that has proved immensely influential across diverse disciplines, Foucault highlights how these modes of objectification serve as operations of power. Drawing on the model of a Panoptic prison, Foucault argues that as individuals become aware of the gaze of an authoritative other, they internalize that image of themselves and police their own behavior accordingly. Knowing that we are observed by others, we learn to know ourselves in this visual way, and cultivate ourselves to produce the desired appearance.

Feminist theorists, famously Laura Mulvey and Iris Marion Young, have developed Foucault's approach, arguing that historically women in particular have been caught within an objectifying male gaze which invests specific parts of the female body with sexual meaning. Rosalind Gill highlights how this issue is still relevant within a post-feminist context, arguing that there has been a shift in popular culture towards a "knowing and deliberate re-sexualization and re-commodification of women's bodies, and men's too" (101), as exemplified in the proliferation of sexualized imagery in advertising, magazines, and popular television programs. Gill's concern is that the emergence of new femininities organized around women's sexual confidence and sexualized selfpresentation should not be celebrated as a move away from passive objectification; rather, she argues that it reflects a shift "from an external male judging gaze to a self-policing narcissistic gaze" (104). By offering women the promise of power if they "choose" to make themselves an object of desire, sexual objectification is disguised as agentic sexual subjectification. Thus we learn to know ourselves and others through analyzing the contours and colors of our bodies, the size and shape of our outline and individual parts, and the shades and luminosity of our skin, eyes and hair. Certain areas of our body take on particular significance for us by contributing to or detracting from our ability to achieve an idealized "attractive" body image, and techniques of self-cultivation such as dieting, fitness regimes and beauty practices are orientated towards achieving this elusive ideal. Susan Bordo and Angela McRobbie have highlighted how this dominance of the visual image can consume an individual's attention 
and alienate them from their own bodily experience to the extent of triggering extreme behaviors with potentially severe health risks, as in the case of cosmetic surgery or eating disorders.

These theorizations all emphasize the scopic through their use of concepts such as observation, examination, and the gaze. The process of making sense of our embodied self as a visual image is reinforced on a daily basis whenever we check our reflection in a mirror or inspect ourselves in photographs, as well as through the relentless barrage of visual representations of the body in popular media such as newspapers and magazines, billboards, television and the internet. The philosopher Shusterman frames this issue in terms of body consciousness, arguing that our attention is: "excessively directed toward a consciousness of how one's body appears to others in terms of entrenched societal norms of attractive appearance ... Virtually no attention is directed toward examining and sharpening the consciousness of one's actual bodily feelings and actions ..." (6) The anthropologist Csordas argues for the development of "somatic modes of attention," suggesting that this involves attending not only to the body, but with the body: "To attend to a bodily sensation is not to attend to the body as an isolated object, but to attend to the body's situation in the world ... Attention to a bodily sensation can thus become a mode of attending to the intersubjective milieu that gives rise to that sensation. Thus one is paying attention with one's body." (138) In the field of dance studies, Dorothee Legrand and Suzanne Ravn argue that the bodily attentiveness developed through the daily praxis of dancers enables them to know themselves in a way that does not objectify their body as a visual image, but rather is better understood as a kind of self-recognition, an awareness of their own subjectivity-in-process. Dancer and philosopher Maxine Sheets-Johnstone particularly draws attention to improvised social dancing, arguing that, while other bodily practices are often orientated towards fitness, competition or the achievement of particular goals or forms, improvised social dancing is arguably unique in its relatively free exploration of the possibilities of bodily movement. Sheets-Johnstone describes this as "thinking in movement" and argues that is a powerful way of thinking as our bodies, rather than about bodies, thus echoing Csordas' notion of attending with our bodies. Unlike staged forms of dance, social dancing does not have the same visual imperative of performances offered explicitly for an audience's gaze; indeed, it has little intention beyond its own existence as an experience of dancing.

This article thus contributes to a wider shift in the social sciences and humanities towards a more affirmative politics of the body. While the belief that focusing on somatic experience can be transformational in a positive or spiritual sense is not new-for centuries practitioners of many kinds of bodily practices such as yoga, pilates, forms of martial arts, 
dancers and indeed sport more generally, have described positive, pleasurable, and transformative effects of developing enhanced somatic awareness - this shift is a more recent trend within the academy, linked to a growing acceptance and theoretical engagement across disciplines with three related areas of research: haptic and kinesthetic experience (see Bannon and Holt, Bacon, Shusterman, Barber, Manning); affect and emotion (see Wetherel, Leys, Clough, Halley); and practice-based or practice-led forms of research (see Mäkelä et al., Hamilton et al., Rust et $a l$.$) .$

\section{Empirical Context and Method}

The empirical work presented in this article was undertaken in 2013 as part of my doctoral study, funded by the UK's Economic and Social Research Council (ESRC). The methodological approach used is highly participatory, based on ethnographic methods of participant-observation and qualitative interviews but also drawing on elements of autoethnography, phenomenology, and reflexive practice. The study was prompted by, and is underpinned by, a decade of personal experience as a social salsa dancer. The field of research for the study is defined as social dancing at salsa congresses, particularly focusing on a form of salsa known as On2 or New York style. This focus on congresses provides a counterpoint to existing ethnographies of localised salsa scenes (see Pušnik and Sicherl, Johnson, Gibson, Skinner, Schneider, Pietrobruno, Kapcha, Urquia). Congresses are weekend festivals which provide opportunities for dancers from many different countries to interact, to learn from more experienced dancers through classes and performances, and primarily, to enjoy social dancing with people from across the world. Congresses are thus the physical manifestation of an international community united through a shared engagement in an affective, intersubjective bodily practice. Congresses are residential events, enabling the dancing to continue all weekend with only brief pauses for sleep; for example, the website for the Berlin Salsa Congress 2013 advertises 11 hours of uninterrupted social dancing from $11 \mathrm{pm}$ to $10 \mathrm{am}$, with classes beginning half an hour later. ${ }^{1}$ This makes congresses a particularly intense form of social interaction, and thus a rich site for social enquiry. The residential nature of the event also contributes to a sense of being separated from one's everyday working life, and are only attended by those who really want to dance, unlike local salsa nights which may attract a more mixed crowd of party-goers in addition to committed dancers. The embodied experience of social dancing at congresses is therefore generally

\footnotetext{
${ }^{1}$ See www.berlinsalsacongress.net
} 
of higher intensity and technical skill than local salsa events and is characterized by a sense of space and time being suspended.

It is important to note that this contemporary, globalised context of salsa differs from specific Latin American contexts, in particular Cuba and Puerto Rico where salsa music is part of mainstream culture and social dancing is woven into the fabric of everyday social gatherings. In contrast, congresses are events specifically organized for the express purpose of dancing, which target a multi-cultural and globally mobile community of dancers of many nationalities and cultural backgrounds ${ }^{2}$. This does raise questions concerning the cultural appropriation and commodification (see Skeggs) of an historically ethnicized bodily practice, issues which have been explored in some depth within the existing literature on social salsa dancing: Schneider's study of the Sydney salsa scene describes how the values and meanings attached to the dance "differ in the particular relocations of the cultural phenomenon in different parts of the world" (Community unpaginated); Pušnik and Sicherl examine the Slovenian scene as a specific local, post-industrial site of a "global cultural industry of salsa" (108); and Pietrobruno's study of the Montreal scene highlights tensions between salsa as a symbol of Latino identity and the global commercialization of salsa as a cultural commodity. In salsa scenes around the world but particularly within the congress context, there is a sense in which salsa is "de-culturalized", detached from Latino culture and re-constituted with new embodied norms emerging from the interaction of people from many different backgrounds sharing an interest in a particular bodily practice. The international setting of congresses also raises the question of who has the financial means and leisure time to attend these events. In many local settings, club entry and salsa classes are available for little or no cost, but congresses incur the cost of overseas travel and accommodation. Low cost airlines, budget hotels and heavily discounted advance sales of event passes do make many events surprisingly affordable (200-300€), and in my experience many dancers with low incomes and inflexible working schedules somehow manage to find ways

\footnotetext{
${ }^{2}$ It is important to understand that the social salsa dancing featured in this article is quite different from the kind of ballroom salsa dancing which is regularly featured on television programs such as Strictly Come Dancing (UK) or Dancing With The Stars (US, Canada) and as a result tends to influence the general public's understanding of salsa. Ballroom dancing is orientated strongly around competitions, and consequently is far more rigidly stylized, emphasizing the achievement of prescribed lines and shapes with the body. In contrast, very few salsa congresses have any formal competitive element, rather the focus is on skill and playfulness in improvising to music with many different partners. Social salsa dancing thus more readily accommodates individual movement styles, and even the incorporation of elements from other dance forms such as hip-hop, tango, ballet, contemporary or Bollywood.
} 
of attending. One dancer I interviewed described how she did not drink or smoke within her local social scene, claiming that the money she saved was enough for her to attend a congress every other month instead. Yet questions remain about who is and who is not able to access the congress space and therefore any affirmative potential that social salsa dancing within this context might offer.

There is another fundamental issue to consider in any analysis of social salsa dancing: namely, that of gender roles and relations. Salsa is conventionally structured in couples comprising a male leader and female follower, and this immediately raises important questions for a feminist perspective in particular, about the gendered power dynamics of salsa as an embodied practice, the intersection of the technical roles of leader and follower with gendered performances, and issues around heteronormativity. Indeed, the affective tensions between my enjoyment of following and my feminist discomfort with the gendered structure of the dance were largely responsible for prompting this research project in the first place. In my wider doctoral study I tackle these issues in detail, and although the present article focuses on the cultivation of tactile, kinesthetic and musical values, I draw on accounts of both female and male dancers in order to highlight some of the ways in which this process is gendered. It should also be noted that, in practice, the male-lead/femalefollow structure is by no means rigidly adhered to in social salsa dancing; although dancing the non-conventional role for one's gender does occasionally elicit a curious look, in general it is widely accepted. As Britte Schneider notes in her study of queerness in salsa, "it is seen as rather unproblematic that people can easily perform the 'wrong' role and may even enjoy it and be really good at it" (Heteronormativity 564). Indeed, taking on the role of leader was an important methodological component of my doctoral study, and reactions from other dancers were overwhelmingly positive.

Focusing on congresses presents certain methodological challenges for fieldwork. The residential nature of congresses provides a stronger sense of being immersed in the field, a central tenet of the ethnographic method (see Geertz, Csordas), yet the events are spatially and temporally transient and multi-sited (see Marcus), lasting only a weekend and held in a different geographical location each week, often with events occurring simultaneously in more than one location. ${ }^{3}$ Thus both the field and the researcher are moving in a geographical sense. This has various practical implications, and the events included in this study were partly selfselecting based on the relative costs of flights and accommodation and the

\footnotetext{
${ }^{3}$ See online listings of salsa events at www.festivalsero.com.
} 
dates on which they fall within the international salsa calendar. During the course of the study, I attended nine international salsa congresses, in Amsterdam, Zagreb, Zurich, Timisoara, Istanbul, Milan, London, San Juan, and New York. Although the study primarily focuses on fieldwork at congresses, this clearly limits the time spent in the field, and for this reason, I also participated over extended periods in the local salsa scenes of London and New York, as two of the biggest and most internationalized scenes.

Over the course of the doctoral study, I gathered over 70 hours of audio recordings of interviews and informal group discussions, and kept detailed notes about my embodied experiences, interactions and conversations with other dancers on and around the dance floor. The study is not intended to provide a representative sample of the entire salsa community; instead the study explores questions of embodied subjectivities and intersubjectivities through the experiences and stories of individuals who participate in the bodily practice of social salsa dancing at salsa congresses. At the congresses I interacted with an extremely wide range of nationalities, and those I interviewed resided in the United Kingdom, United States, France, Spain, Germany, Holland, Norway, Switzerland, Turkey, Romania and Croatia but claimed many other nationalities, ethnicities or heritages, including Russian, Italian, Jamaican, Greek, Jewish, Australian, Indian, Antillian, Dominican, and Puerto Rican. I found this international mobility to be common among this community of salsa dancers, with many individuals expressing complex ethnic/racial/national identifications, often describing themselves as being "part X and part Y, grew up in Z, but now live in ..." etc. I interacted with some male and female dancers who identified as homosexual and one male dancer who defined his sexuality as "fluid," but the majority identified as heterosexual. Their ages ranged from early 20 s to 50 s, and their experience of salsa ranged from a year's experience of social dancing and attending one congress, to full-time professional teachers and performers who have danced salsa and attended congresses all over the world for many years. Although some individuals, particularly those with Latino heritage, had prior experience of salsa music and dance from their childhood, all the participants described an explicit process of learning to dance salsa through attending workshops and specific salsa events. This reinforces the point made earlier that social salsa dancing within the congress setting is a bodily practice which is largely dislocated from Latino culture, forming a community of practice (see Schneider, Community) rather than of national or ethnic identification.

The interviews were in-depth and open-ended, usually lasting around an hour but some extending to two hours or longer where the discussion did not feel finished and the respondents were willing to continue. In the interviews, I used a prepared interview schedule only 
when necessary to prompt discussion; in general I encouraged respondents to talk freely and my familiarity with the research setting enabled me to quickly establish good rapport with all the respondents, resulting in most discussions feeling more like an informal conversation between acquaintances than a formal interview. My interaction with all of the respondents extended to the dance floor, by dancing with them, observing them dance, and generally "hanging out" with them within the social dance context. I also participated in and observed classes in order to better understand how skills and values are explicitly taught and cultivated within the salsa community. However, these classes were very much focused on developing the tools for social dancing; thus during the classes, during congresses in general, and throughout this study, the emphasis remained on social dancing.

The extent of my previous experience within the international salsa community meant that I already had some acquaintance with many of the participants as dancers, but prior to this study I knew very little or nothing about their background or motivations beyond my experience of them on the dance floor. My relations to the participants in this study were, and remain, complex, combining embodied subject positions of researcher, fellow dancer of different relative competencies, dance partner-as a leader or follower - student, teacher, or simply friend. The dynamics of these relations shifted depending on the specific circumstances and the individual participant, highlighting the need to be constantly reflexive about issues of power and representation. Other potential ethical issues pertaining to the discussion of personal and possibly sensitive topics such as body image, sexuality, and self-expression were given due consideration and mitigated through informed consent, confidentiality and pseudonyms where requested by the participant. ${ }^{4}$

\section{Findings}

\section{a) Developing senses and skills in movement, touch, and musicality}

From a beginner's first encounter with salsa, three kinds of senses and skills are specifically cultivated in terms of developing awareness and responsiveness: in one's bodily movements; in the contact with a partner; and in listening to the music. Social salsa dancing is based on a basic pattern of steps and weight shifts which correspond to important beats in the music. This basic pattern provides enough structure to facilitate two people dancing together but allows plenty of flexibility to respond to the

\footnotetext{
${ }^{4}$ The study was fully approved by the Arts and Humanities Panel of the King's College London Research Ethics Committee (REP-H/11/12-43).
} 
music and incorporate individual styles of movement. In the beginner classes I observed during this study, almost all the instruction focused on participants grasping these basic movements, being able to fit these to different tempi of music, and being able to successfully coordinate their movements with many different partners.

As they learn specific patterns of movement, beginners start to develop more understanding of which parts of their body are moving, and the different ways they can move. Julia, a dancer of six years experience, recalls her early experiences of learning salsa: "The awareness of your body I think comes first, I think it's the first thing you need to know, and understand where your shoulders are, what is their function, what is the function of your torso, your legs, and all of that." Her comment about "understanding where your shoulders are" refers to the development of a proprioceptive and kinesthetic awareness of how your shoulders feel when they move, and discovering how to move them in specific ways; for example, a popular exercise taught in classes is to alternate your shoulders forward and backwards quickly but without moving your ribcage. Similarly, Julia mentions "the function of your torso"; another common exercise is to work on contracting and releasing your chest, ribcage, upper abdominals, lower abdominals then pelvis in sequence, creating the feel of a ripple moving down through your body. These kinds of body isolation exercises develop targeted control of different parts of your body, lead to greater flexibility and range of movement, and afford you more possibilities of movement when social dancing. A relatively new dancer, Joseph, describes his experience of developing this kind of proprioceptive and kinesthetic awareness in clearly positive and transformational terms:

[Salsa] changes the whole way you view your body. The way you know it can express. I had a lesson recently, and the very first thing we did was connecting with your body, sounds weird, something I would have laughed the heck out of six months ago. But just trying to feel what your body parts are doing, where muscles are ... that thing about feeling the floor, and feeling where you are, that has all come, I feel like I'm learning so much from dancing ... it's taken me on the most random paths, and I think, benefited me immensely.

Joseph's reflection on how he would previously have laughed at the notion of connecting with his body illustrates the way in which kinesthetic values emerge through the practice of social dancing. He makes a similar reflection about valuing musicality: "Now I have an understanding of the music, and how it fits in, and how you can be in the music, or-I would never had said this six months ago, 'be in the music' [laughs]_but yeah, it just feels comfortable to say that now." Natasha, a more experienced dancer, reiterates the value of musicality within salsa, specifically identifying it as a measure of one's status as a dancer: "When I see that 
someone is musical, someone is listening to the music ... I think that's what differentiates solid dancers from great dancers."

As illustrated, social salsa dancing cultivates awareness and skill in how you move your body and in how these movements reflect the music. These elements are critical to being able to coordinate with a partner and create shared movement and musical expression together. When learning new patterns of movement in classes, it is usual for partners to constantly rotate so that they learn how to adapt to many different partners. Some level of coordination is easily achieved if both partners match their movements to the music, but as each individual has a different physique and existing habits of movement, even simple patterns feel different with each partner. This awareness is explicitly cultivated through the development of one's sense of touch. When social dancing, much of the time the partners are only physically connected through their fingers, and so must develop an awareness of different qualities of touch. The lightness or firmness of a touch, the level of tension in the fingers, wrists and arms, enliven this contact into a highly expressive form of communication. In one class, we spent considerable time walking around the room in pairs, palm touching palm, taking turns to close our eyes and focusing on communicating and coordinating our movement with our partner simply through that contact. Magna, a well known full-time dancer and instructor, maintains that the tactile communication in dance is an extension of everyday experiences of touch:

So if you were going to comfort somebody, right? Just natural reaction, if something was happening with you, I would never be like, 'I'm so sorry, are you ok?' [puts her hand on my shoulder very limply, causing me to repress an unexpected urge to shudder] ... And I also wouldn't be like, 'Listen, you know what, it's all going to be alright' [suddenly grips my shoulder hard enough to be uncomfortable, catching me by surprise and making me wince], you know, I'm not gonna break your shoulder! ... I'd just be like, 'Listen' [eases her tight grip to a gentle but solid touch]. People know how to touch, actually ... You know the right touch. You've had a friend cry to you, and you've had to hold their hand or something, you know the right touch.

My interview with Magna was followed by a practical session, in which she went into great detail about the quality of tactile connection possible at a highly advanced level of social salsa dancing. She demonstrated how even the simplest touch has elements of compression, movement and release, and that these elements allow energy to flow between partners. She showed how the smallest details of movement can carry meaning, such as a slight lifting of the left hand signaling the release 
of weight from the left leg, or a sharp intake of breath signaling the initiation of a particularly dynamic movement.

As I have shown, specific senses and skills are developed and valued within the context of social salsa dancing. In this context, there is a clear emphasis on proprioceptive and kinesthetic awareness and control, awareness and understanding of musical tempi and rhythmic patterns, and awareness and subtlety in tactile communication. Social dancing depends on these skills to enable individuals to move together coherently as partners, and to adapt constantly to new partners.

\section{b) Valuing connection and attention}

As demonstrated above, social salsa dancing is fundamentally based on moving together with another individual and the music. Dancers consistently refer to this intercorporeal experience in terms of connection; as Heike says, "Salsa is just about the connection, and what you are able to do together." As described in the previous section, the physical contact between partners is usually simply through the fingers, sometimes a touch on the partner's shoulder or back, yet the experience of feeling connected encompasses much more than just this contact. When partners have a strong connection, they share a bodily understanding of the energy, tempo and character of the music, and the energy flowing through their physical contact, and together are able to create the momentum and direction of movement. As the quotations below will illustrate, there is a sense of an embodied union, a pooling of individual bodily resources to create something more, as Natasha describes:

Those are the moments you remember the most, when you meet someone for the very first time and you have an amazing dance, like you just connect on that level so well, like the way you listen to the music, and you feed off each other and you inspire each other during the dance, those are the moments ... You're not trying to compete with your partner, you're trying to dance with them, not be better than them or be better than anyone else. It's just about dancing with them ... It's just that much stronger, and better, the feeling is much better when you're sharing something with someone.

Speaking from my experience as a participant, there is something incredibly empowering and joyful in this experience of connection, a sense of being able to be more in partnership with another person than you can be by yourself. Julian describes this in terms of your partner feeling like an extension of your body:

Each dance is different, because you have a different connection with each girl. And that's what we are looking for ... we are looking for the perfect connection ... You feel like your two 
bodies make only one. Because you know, like her body is an extension of yours. Like, you don't even need to speak or show with your eyes, to say with your eyes, make this, make that, it just feels that it is something very natural, and, yeah, like the partner is your body. It's the same, it's two bodies in one.

Frankie describes this strength of connection in terms of experiencing "it," where the subjective experience moves beyond "I am dancing," and even beyond "we are dancing," to a kind of meditative state: "If you can figure that out ... so that there is no you, and her, and dance, and music ... you can get to the point where you only experience it, you know. There is no two people, there is just it-it's the music and the dance and the people involved, with no lines to separate them. Then you are going to really enjoy dancing. It's going to take you to another dimension." Being able to experience this kind of connection with a partner is dependent on having the basic skills and understanding of movement, touch and musicality as discussed earlier, and then learning how to deploy these skills whilst paying close attention to your partner and to the music. As Joseph says, "Dancing is about the feelings and reactions to the things you get thrown. You get it, you take it, you play with it, then you give it back." I often hear dancers talk about "listening" to their partner's body. The use of the term listening may be in deference to the three-way relationship between two dancers and the music, but it also serves to evoke a sense of active participation. Listening is more than simply hearing or receiving sound; listening implies actively seeking out the sound, paying attention to its subtleties and complexities. This applies to the connection in salsa, where partners are more than simply feeling the contact and movement of each other's bodies. They try to be alert and responsive to the subtleties of the contact and movement, thus engaging in a highly attentive form of embodied interaction with others. Joseph explains, "You have to adapt with who you're dancing with, and that's what it comes down to ... You're meant to be receptive to what's going on, and try to be attentive, as much as you're having fun." This resonates strongly with Shusterman's call to pay attention to the experience of bodily practices and Csordas' concept of "somatic modes of attention" as discussed earlier in this article.

The notion of paying attention seems to evolve as one gains experience in social salsa dancing. As you initially work on developing the skills and qualities of movement and touch described earlier, the focus of attention is often on your own bodily state, trying to remember and implement specific points of technique, from the very basics such as matching your steps and weight shifts to the correct beats in the music or keeping arms relaxed, to more advanced techniques such as the precise trajectory of arms during complex turn patterns, or executing the correct preparation for multiple spins. As bodily capabilities and awareness 
develop, more experienced dancers are able to shift their attention more towards their partner and to the music. As Julia describes:

As you progress and you become more aware of the music and how it connects with the dance, you find spaces and times where you can express the music without disrupting the symbiotic leading and following. So, I think it's all just about spending more time with it, practicing the dance, and understanding the mechanics, not just mechanics, but the collaboration that happens when you dance with someone.

Magna, one of the most experienced dancers I interviewed, is renowned for being an extremely playful and creative dancer. She describes how she is able to achieve this through paying attention to the minute details of her partner's bodily presence:

And the reason I end up being very present, and the reason I can play as much as I can, is because I'm really paying attention, 'oh, his body weight changed, oh, he took a deep breath here.' I think the more talented you are, the better you are, the better you should be connected. The more you know about how to talk, the better your conversation should be. The more vocabulary you have, the better conversations you should have.

Julia echoes this notion of paying attention to your partner in terms of tuning in: "The perfect dance for me is that ... we focus on each other, and we dance with each other. And we are aware of each other's bodies and, you know, the speed, the strength, the kind of moves that you see the person do, so you really need to tune in." Both Julia and Magna associate a high level of attentiveness between partners with a good dance experience, but Magna is more specific, clearly considering an individual's attentiveness to their partner as a measure of their ability as a dancer. Heike also draws attention to the unique dynamics that exist between each two individual dancers: "[What makes a good dance] is subjective, because you will have a good dance with someone that your friend cannot connect with. Which is also the beauty of the dance, right? ... Salsa is just about the connection, and what you are able to do together ... So level can be judged so differently." Similarly, Julia also highlights the reciprocal character of partner dancing, and describes how both dancers need to be "tuned in" to form a good connection:

So once you have a situation when both people are really tuned in with each other, and understand how-or get a feeling, a sense of what the other person is about, what kind of move does he like, the speed, the expression, and you can connect with that, and work with that, rather than imposing your own style on the other person and making them struggle with it — for me, that I think is the perfect dance. You become less self-involved, and 
it's more about sharing this song with that other person in a way that makes you both happy.

It is interesting to note how Julia interrupts herself at one point in the passage quoted above, correcting herself from "understand" to "get a feeling, a sense." This reflects another way in which the notion of paying attention seems to evolve with experience, in terms of a shift from a deliberate concentration to a more instinctive kind of responsiveness to your partner's activity. Thus Stanley, an experienced dancer, describes how he prefers not to attend classes immediately before social dancing, explaining that it put him in a state of being "too much in my head, and not so much in my body," whereas when he just turned up for the social dancing, he felt more free: "there's not all this thinking blocking my connection with the music and my partner." Heike describes her experience in similar terms, as being in a state of "not mind":

I know that my thoughts can kill a good dance, because I'm thinking about it too much ... And I think, for me, that is a hurdle for me in my dancing. And I feel this is why I enjoy the dance, in a best-case scenario, it is one of the few things in life that makes me stop thinking. One of the very few things. And when I'm in that state of mind, or 'not mind' [mimes quotation marks with her hands], that's when you just-move, and fly, and you don't think about what you're doing.

Given that the leader and follower roles are usually assigned to men and women respectively, it is important to consider to what extent these experiences of connection with a partner are gendered. In beginner classes, the leader role is usually discursively constructed as highly active in directing movement, creating momentum, and avoiding collisions, in contrast to the follower role which is often discursively constructed in passive terms of "just follow what he leads, and don't anticipate." We might expect then, that the notion of paying attention would be more relevant to the follower role, yet to pay attention is clearly to not be passive. The descriptions of connection given above by three male dancers and four female dancers of varying levels of experience are in fact remarkably consistent, and indicate that the roles in practice are far more nuanced and reciprocal than implied by the terms "leader" and "follower." As Julia's comment about both partners "tuning in" illustrates, to create a well connected partnership in social salsa dancing, the leader is required to pay attention to what the follower is doing just as much as the follower is required to pay attention to what the leader is doing.

\section{c) Valuing the embodied process rather than an idealized outcome}

As illustrated above, paying attention in an embodied sense and maintaining connection with a partner is highly valued within the context of social salsa dancing, meaning that one's experience is very much 
concerned with the immediate moment of embodied activity. It is important to remember that social salsa dancing is improvised, and the main intention is not so much to create an aesthetically pleasing dance, but rather to enjoy the process of creating shared movement with a partner in that moment. As Joseph describes, "You're just-you're just, there. You're just there with the music, with the person ... at the end of it, it's all left there, you both give everything to the song, and that is the best. I think that's what you're always looking for, just trying to have all the tools in place so you can express what you're trying to express at the time." Joseph's comment clearly shows how the development of technical skills is primarily in order to be better equipped for those moments of interaction with the music and your partner. A comment by Magna reveals how even the smallest details of the process are valued because they always create a new experience: "When connecting with your partners, there is no moment in your life that is going to repeat itself identically. None. Even if everything looks the same, same song, same part of the dance floor, same lighting, same exact time of the day and everything - he breathed in, this time. And that makes everything different." This sense of discovery through our embodied interactions with others was a commonly articulated theme among the participants, and often specifically associated with development of the self. As Frankie explains, "When you connect with somebody, it's not just connecting with them, it's connecting with the music, it's connecting with yourself, and learning about yourself." A comment by Natasha illustrates how this potential for developing the self serves as a motivation for dancers to constantly seek new partners: "I want to dance with that person, because he will bring something new ... show me what you know, I want to learn something, take something from you." Michael also highlighted this as a key incentive for attending congresses, as these events expose you to many new dancers and different styles. He claimed that dancers often quite deliberately "work on themselves" by seeking out new partners who will provide them with new experiences of movement and musicality on the dance floor. As Magna reflects, "You can come up with a move, but even that has it's limits, you know? But the human element is the part that's ever-changing, if you kinda focus on that, there's no end to what you'll discover." The interesting and potentially emancipatory aspect of this intersubjective approach to working on the self is that it does not follow a trajectory towards a normatively prescribed yet highly elusive ideal, but rather has the sense of a ongoing process of discovery. Frankie describes this in terms of endless possibility, or infinity: "There's only one place to go, and that's here [points to himself]. And because we're dealing with infinity, we're dealing with endless possibility, then all of us are at zero ... No matter how big we get, infinity keeps going." Joseph describes his experience of dancing as a mode of working on the self in similarly affirmative and exploratory terms: 
It's another dimension. But it's something that I would never have known until someone mentioned it, and now it's something for me to explore and think about ... that's what I want now. I didn't realize ... just like made me think about it completely differently. And now, like, there's much, so much, work to do, right! [laughs]. Like, work, but not work, because I enjoy it ... thinking about how I do body isolations, how I listen to the music, how I use that to express, how I understand how my body's feeling.

Yet at the same time as being open-ended, this idea of working on the self is also immediately achievable, as Julia explains:

I think you become more aware of your body, what your body can do ... there is room to grow, there is room to develop, and you're actually able to cover that distance ... I think the most I wanted was just to be comfortable in my own skin, and just to do what I enjoy. And I enjoy [salsa] very much because it gives you a big release and brings lots of happiness. So you know, as long as I was getting that, it was also helping me develop myself and become more comfortable with myself, and as a result, you know, more comfortable with everybody else.

Normative pressure to achieve idealized bodily images does not simply evaporate, but the extracts below illustrate how the shifting of values from visual appearance to attentive interactions with others helps to alleviate this pressure. Magna describes how she went through a period of dancing where she was highly conscious of her appearance, but how she subsequently recognised that this was detracting from the immediate moment of interaction with her partner:

I've gone through a phase where I was like, 'Yeah, I'm looking good', you know? And then I was, like, that doesn't give me the best connection with my partner. When I have that attitude, I'm not here with this person. I'm here with myself, my environment is in here [taps side of head], the music is here, and me, and my partner is here too [still tapping head, laughing], you know?! So I went through that phase too, and then I just realized that, I was like, why don't I just stay home and look at myself in the mirror and say beautiful things to myself?! Because I want to connect with another human being.

Magna later described how she now tends to dress fairly casually for dancing, often wearing jeans rather than a dress even for big events, because it helps her to feel less concerned about presenting a certain appearance and more able to concentrate on the process of dancing with a partner. As Magna's experience illustrates, the imperative to pay attention in the moment of dancing and stay connected with your partner helps to 
anchor oneself in the embodied experience of the moment and alleviates the concerns about achieving normative ideals of appearance. Joseph similarly describes how focusing on the feeling of dancing minimizes his concern about his appearance:

In your head, you think 'this feels natural, I've practiced a lot of this stuff before and I enjoy how they make me feel'. That hopefully translates into me looking good. And that's as far as the thinking goes. It doesn't go any further than that ... So if you come across and say, 'I think you look really good' ... I'd prefer 'you look like you're enjoying it, and I enjoy what you're doing.'

Joseph's claim that he would prefer to be recognized and praised for the emotion he appears to be feeling, than for his actual appearance as such, shows how "feeling" is a value that is cultivated within social salsa dancing, and serves to de-emphasize appearance. This is consistent with an oft-repeated instruction I heard during classes, "Concentrate on how it feels!" One instructor continually reminded us that there are no mirrors on the dance floor so we should get used to feeling good and not worry about looking good. As he put it, "Pretty or not, if you're feeling it, you're gonna look cool" (Neeraj). Heike, who revealed a history of eating disorders in her interview, clearly recognizes the emancipatory potential of salsa as a bodily practice which values movement and feeling above appearance:

I'm trying to let [salsa] change me. I think I need salsa sometimes, I feel like, in a very, um, let's say, in a world that is very body-focused at times, where I know, because I have eating problems myself, I'm conscious about the influences we get from advertising and all that, because I feel like, to a certain extent, I was a victim of it myself. So salsa has always helped me, just to witness how it brings together all body shapes, women that have the most amazing movements, and would not care what size their ass is! As someone that unfortunately still cares too much about how I look, or if I've gained weight or not, it helps me, and I think it's been very good for me to be doing that ... So, yeah, it's therapeutic for me, almost. I'm trying to, just, not care anymore. And I love watching it, how people don't care, when they dance.

In the extracts above, Magna, Joseph, Neeraj, and Heike all describe how the emphasis on quality of movement, connection with your partner, and a sense of feeling good all help to alleviate the desire to look good. It is revealing, however, to note how this pressure to look good is experienced differently by men and women. In Magna's comment about the mirror and Heike's references to "what size their ass is" and "if I've gained weight," looking good is clearly about the visual appearance of their bodies as an 
object for the gaze of others. In contrast, Joseph's understanding of looking good seems to relate more to whether he appears to a spectator as a skillful and playful dancer. This directly recalls the argument made by Mulvey, Young and many others, discussed in the Theoretical context section above, that men are positioned more as capable subjects and women more as visible objects.

I finish this analysis section with a final quotation from Heike which draws together the main threads of the arguments presented in this article. Heike sees the development of certain skills and qualities in movement, touch and musicality as offering new criteria for making sense of ourselves and each other. Moreover she recognizes that this particular mode of judgment is embedded in the immediacy of the process of dancing:

I think what it is, is basically that, you depart from a certain level of judgment because you have something else that you are judging everyone on. And it's completely different criteria. It's not the look, it's not about the shape, it's just how you are dancing right now. So everyone is sharing that quest for a good dance. And you will not care how that dancer looks, as long as he's a good dancer, right? So that's common ground, and that brought everyone here, that intention, that reason why we're in a certain place, is the dancing, and that's all that matters.

Heike's comment highlights the inescapable nature of judgment, in that one set of criteria is only ever displaced or alleviated by another set of criteria. Important criteria within the context of social salsa dancing are quality of movement and touch, musicality, and "feeling good," and whilst these values may well be normatively constructed in the verbal discourse of the salsa community, in the affective, intercorporeal practice of social dancing they are difficult to pin down, leaving room for slippage between different interpretations. However, as in any value system, these tactile, kinesthetic values of movement also have the capacity to produce unequal power dynamics, and this presents interesting avenues for research exploring what issues arise through this shift towards embodied values of movement and touch, musicality, and "feeling good." For example, what does it mean for the process of self-cultivation if one fails to "feel good" or struggles to establish a strong connection with a partner?

\section{Conclusion}

This article contributes to philosophical discourses on embodied subjectivities and brings a new perspective to existing literature on salsa dancing by tracing the development of specific skills and values through the bodily practice of social salsa dancing. Dancers learn to execute 
specific movements, to improvise using these movements to different music, and to adapt their movements to a specific partner. In this way, dancers develop particular modes of embodied sense-making, specifically kinesthetic, tactile and musical. By developing these modes of awareness, dancers are able to experience a highly intersubjective form of embodiment, conceptualized by participants in terms of connection. The process and experience of connecting with a partner and the music is valued for the joy and potential for self-discovery that it offers, and in this context, working on the self is interpreted as developing skills and awareness that will enhance the experience of one's body in process with other bodies.

There are interesting tensions between this affirmation of social salsa dancing as a potentially emancipatory bodily practice and more familiar critiques of salsa as a normatively structured and structuring practice. I believe that keeping these perspectives in tension with one another and drawing out different aspects of embodied experience without losing sight of either perspective, will produce rich avenues for future research. For example, further exploration of the idea that connecting with others is experienced as a process of self-discovery would contribute to discourses on intersubjectivity, but also raises the question of power dynamics in embodied relations, not only in gender terms but between dancers with different levels of ability and experience such as instructors and students. Dancing with a more experienced or skilled dancer can be exhilarating in the sense of going beyond your previous experience, but it also sets up unequal and potentially problematic power dynamics, in which one partner is somewhat at the mercy of the other to be able to "feel good." These power dynamics may also change depending on whether it is the leader or the follower that is more experienced, thus intersecting with gender dynamics, and so we begin to form a picture of the highly complex intersectionality of skill/experience with leader/follower roles and with gender roles. Furthermore, examining the intersection between gender roles and leader/follower roles raises the question of the extent to which these roles are sexualized and therefore heteronomative. Salsa dancing and partner dancing more generally is often criticized for being heteronormative-Schneider describes it as "the performance of sexualized dichotomous gender positions" (Heteronormativity 554)-but do we interpret it as sexualized simply because it usually involves one man and one women engaging in a physically intimate and pleasurable activity, regardless of their personal relationships or sexual orientations? Is it still sexualized and heteronormative when a gay man dances with a heterosexual woman, or a lesbian woman? Or when a woman dances with her uncle or her brother, or any other man that she does not sexually desire? Maintaining the tension between affirmative and normative perspectives enriches the analysis by highlighting the complex relations between the cultivation of tactile, kinesthetic and musical values, the 
experience of bodily pleasure, and the construction of normative gender roles and unequal power dynamics. Further work on the development of kinesthetic and tactile senses can also consider the implications for the research process itself, engaging with phenomenological and practicebased literature to explore how we as researchers might pay attention not only to our bodies, but also with our bodies.

\section{Works Cited}

BACON, Jane. "The Voice of her Body: Somatic Practices as a Basis for Creative Research Methodology." Journal of Dance and Somatic Practices 2, no. 1 (2010): 63-74.

BAnNOn, Fiona and Duncan Holt. "Touch: Experience and Knowledge." Journal of Dance and Somatic Practices 3, no. 1-2 (2011): 215-227.

BARBER, D. "Somaesthetic Awareness and Artistic Practice: A Review Essay." International Journal of Education \& the Arts 9 (2008): n. pag.

BARbOUR, Karen. "Autoethnographic Writing and Solo Dance Performance." Cultural Studies $<=>$ Critical Methodologies 12, no. 1 (2012): 67-71.

Bordo, Susan. Unbearable Weight: Feminism, Western Culture, and the Body. Berkeley: University of California Press, 1993.

BORLAND, Katherine. "Embracing Difference: Salsa Fever in New Jersey." Journal of American Folklore 122, no. 486 (2009): 466492.

Clough, Patricia Ticineto and Jean Halley (Eds.). The Affective Turn: Theorising the Social. Durham and London: Duke University Press, 2007.

CSORDAS, Thomas. "Somatic Modes of Attention." Cultural Anthropology 8, no.2 (1993): 135-156.

Foucault, Michel. Discipline and Punish: The Birth of the Prison. Trans. Alan Sheridan. New York: Vintage, 1977.

-. The Care of the Self, Volume 3: The History of Sexuality. Trans. Robert Hurley. New York: Vintage, 1986. 
GEERTZ, Clifford. The Interpretation of Cultures: Selected Essays. New York: Basic Books, 1973.

GiBson, Jade. "Short Steps to Freedom: Interfaces, Spaces, and Imaginaries within Cape Jazz Social Dance and the Emerging Salsa Scene in Cape Town." Papers from the Fifth South African Dance Conference (2008): 113-122.

GILL, Rosalind. "From Sexual Objectification to Sexual Subjectification: The Resexualisation of Women's Bodies in the Media." Feminist Media Studies 3, no. 1 (2003): 100-106.

HAmilton, Jillian and Luke JAANiste. "Content, Structure, and Orientations of the Practice-Led Exegesis." Papers from Art.Media.Design: Writing Intersections Conference. Swinburne University of Technology, Sydney. 2009.

HEYES, Cressida J. Self Transformations: Foucault, Ethics, and Normalised Bodies. Oxford: Oxford University Press, 2007.

Hutchinson, Sydney. "Mambo on 2: The Birth of a New Form of Dance in New York City." Centro Journal 16, no. 2 (2004): 108-137.

JoHnson, Tamara. "Transgressing the Territories of Dance: Spatiality and Salsa in North Carolina." Papers from the Congress of the Latin America Studies Association. 11-14 June 2009, Rio de Janeiro, Brazil. 10 Dec. 2011.

KAPCHAN, Deborah. "Performing Femininity: Dance and Literature in German Modernism." Series Cultural History and Literary Imagination no. 12. Oxford: Peter Lang, 2006.

LEYS, Ruth. "The Turn to Affect: A Critique." Critical Inquiry 37, no. 3 (2011): 434-472.

LEGRAND, Dorothee and Suzanne RAVN. "Perceiving Subjectivity in Bodily Movement: The Case of Dancers." Phenomenology and the Cognitive Sciences 8, no. 3 (2009): 389-408.

MÄKElÄ, Maari, et al. "On Reflecting and Making in Artistic Research." Journal of Research Practice 7, no. 1, (2011).

Manning, Erin. Politics of Touch: Sense, Movement, Sovereignty. Minneapolis \& London: University of Minnesota Press, 2007. 
MARCUS, George. "Ethnography in/of the World System: The Emergence of Multi-Sited Ethnography." Annual Review of Anthropology 24 (1995): 95-117.

MCRobiIE, Angela. The Aftermath of Feminism: Gender, Culture, and Social Change. London: SAGE, 2009.

Merleau-Ponty, Maurice. Phenomenology of Perception. Trans. Donald A. Landes. London: Routledge and Kegan Paul. 2012.

Mulvey, Laura. "Visual Pleasure and Narrative Cinema." Screen 16, no. 3 (1975): 6-18.

PIETRobruno, Sheenagh. Salsa and its Transnational Moves. Oxford: Lexington, 2006.

PUŠNIK, Maruša and Kristina SICHERL. "Relocating and Personalising Salsa in Slovenia: To Dance is to Communicate." Anthropological Notebooks 16, no. 3 (2010): 107-123.

Rust, Chris, Judith MotTRAm, and Jeremy TILl. Review of Practice-led Research in Art, Design \& Architecture. Arts and Humanities Research Council, UK. 2007.

SCHNEIDER, Britta. "Community, Commodification, Cosmopolitanism: Salsa and Ideologies of Language in Transnational Settings." Working Papers in Urban Language and Literacies 55 (2008).

-. "Heteronormativity and Queerness in Transnational Heterosexual Salsa Communities." Discourse and Society 24, no. 5 (2013): 553571.

SheETS-Johnstone, Maxine. The Primacy of Movement: Advances in Consciousness Research. Expanded $2^{\text {nd }}$ ed. Philadelphia: John Bejamins Publishing Co., 2011.

Shusterman, Richard. Body Consciousness: A Philosophy of Mindfulness and Somaesthetics. Cambridge: Cambridge University Press, 2008.

SkEGGS, Beverley. "The Re-Branding of Class: Propertising Culture". In DEvine et al. (Eds.). Rethinking Class: Culture, Identities, and Lifestyle. Hampshire: Palgrave MacMillan, 2005.

SKINNER, Jonathan. "Women Dancing Back — and Forth: Resistance and Self-Regulation in Belfast Salsa." Dance Research Journal 40, no. 1 (2008): 65-77. 
URQUiA, Norman. “The Re-Branding of Salsa in London's Dance Clubs: How an Ethnicised Form of Cultural Capital was Institutionalised." Leisure Studies 24, no. 4 (2005): 385-397.

Wetherell, Margaret. Affect and Emotion: A New Social Science Understanding. London: SAGE. 2012.

YounG, Iris Marion. "Throwing Like a Girl: A Phenomenology of Feminine Body Comportment, Motility and Spatiality." On Female Body Experience: "Throwing Like a Girl" and Other Essays. Oxford: Oxford University Press, 2005. 